\title{
Statins Reduce Mortality After Non-severe but Not After Severe Pneumonia: A Systematic Review and Meta-Analysis
}

\author{
Mingwang $\mathrm{Jia}^{1,2,3}$, Wenjie Huang ${ }^{2 *}, \mathrm{Li} \mathrm{Li}^{2}$, Zhong $\mathrm{Xu}^{3}$, Lichan $\mathrm{Wu}^{3}$ \\ ${ }^{1}$ Southern Medical University, Guangzhou, Guangdong Province, P. R. China; ${ }^{2}$ Department of Respiratory Medicine, \\ Liuhuaqiao Hospital, Guangzhou, Guangdong Province, China; ${ }^{3}$ Department of Intensive Care Unit, The Third \\ Affiliated Hospital of Guangzhou Medical University, Guangzhou, Guangdong Province, P. R. China.
}

Received, May 10, 2015; Revised, July 16, 2015; Accepted, August 5, 2015; Published, August 8, 2015

\begin{abstract}
PURPOSE: The objective of this study was to perform a systematic review and meta-analysis of the effects of statins on mortality for patients with non-severe pneumonia or severe pneumonia. METHODS: PubMed, EMBASE, Cochrane Database of Systematic Reviews, Cochrane central register of controlled trials and Clinicaltrials.gov were searched for the association between statins and non-severe/severe pneumonia. Eligible articles were analyzed in Stata 12.0. RESULTS: The database search yielded a total of 566 potential publications, 24 studies involving 312,309 patients met the eligibility criteria. Pooled unadjusted data showed that statin use was associated with lower mortality after non-severe pneumonia (odds ratio [OR] 0.70, 95\% confidence interval [CI], 0.66-0.73), but not severe pneumonia (OR 1.05; 95\% CI, 0.86-1.28). However, this protective effect of statins was weakened using adjusted estimates (OR 0.78, 95\% CI, 0.75-0.82). Besides, protective effect of statins was attenuated by confounders in a subgroup analysis, especially when accounting for pneumonia severity indicators (OR 0.88; 95\% CI, 0.80-0.96). CONCLUSIONS: Statin use was associated with reduced mortality after non-severe pneumonia but not severe pneumonia and this protective effect was weakened in subgroups.
\end{abstract}

This article is open to POST-PUBLICATION REVIEW. Registered readers (see "For Readers") may comment by clicking on ABSTRACT on the issue's contents page.

\section{INTRODUCTION}

Pneumonia is one of the highest mortality diseases ${ }^{[1]}$. In United States, nearly 4 million adults had community-acquired pneumonia (CAP) per year ${ }^{[2]}$, which caused almost 50,000 deaths and 1.1 million hospital admissions [3, 4]. The incidence of pneumonia was almost 3.3 per 1000 patients for hospitalized patients ${ }^{[5]}$ and the annualized total medical costs reached 14,038 dollars per patient ${ }^{[6]}$. Although great progress had been made in antimicrobial treatment, mortality of pneumonia was still high, especially for severe pneumonia, mortality rate of which was as high as $50 \%{ }^{[7]}$.

Statins, as one of the inhibitors of 3-hydroxy-3-methylglutaryl coenzyme A reductase (HMG-CoA), are able to lower the level of blood cholesterol and used in patients with cardiovascular diseases or to prevent cardiovascular events ${ }^{[8-10]}$. Stains have potential immunomodulatory and anti-inflammatory effects in CAP ${ }^{[11,12]}$. An earlier retrospective cohort study showed that, in bacteremia patients, in-hospital mortality was significantly reduced after using statins ${ }^{[13]}$. Since 2005, researchers have focused more attention on statins in the treatment of infections ${ }^{[14-16]}$. Most of these studies argue that statins are advantageous to outcome and prognosis of patients with infectious diseases. However, Fernandez et al demonstrated that hospital mortality was significantly higher after statin therapy ${ }^{[17]}$. Majumdar et al reported that statins were not associated with reduced mortality in a prospective cohort study of 3415 patients with pneumonia ${ }^{[18]}$. Whether statin use was associated with reduced mortality for patients with pneumonia is still in debate.

In this study, we performed systematic review and meta-analysis to address the roles of statins in non-severe and severe pneumonia. Further, subgroup analysis was conducted taking pneumonia severity, propensity score, comorbidity and smoking status as important confounders.

Corresponding Author: Wenjie Huang, Department of Respiratory Medicine, Liuhuaqiao Hospital, Guangzhou, Guangdong Province, China E-mail: wenjiehuanggg@163.com 


\section{MATERIALS AND METHODS}

Information Sources and Search Strategy

This meta-analysis was conducted according to Preferred Reporting Items for Systematic Reviews and Meta-Analyses (PRISMA) and Meta-analysis of Observational Studies in Epidemiology (MOOSE) recommendations $[19,20]$. PubMed, EMBASE, Cochrane Database of Systematic Reviews, Cochrane central register of controlled trials and Clinicaltrials.gov were searched using the following key terms: (hydroxymethylglutaryl-CoA reductase inhibitors or HMG-CoA reductase inhibitors or simvastatin or lovastatin or pravastatin OR fluvastatin or atorvastatin or rosuvastatin or pitavastatin or statins) and (pneumonia or low-respiratory-tract-infection or lung injury [ALI]or pulmonary injury or acute respiratory distress syndrome [ARDS]). The final date of the literature search was September 31, 2014. There was no publication date, language or status restrictions for searching. "Mortality" was not involved in search strategy for reducing the omission. All studies were downloaded into EndNote 6.0 for further screening. Notably, we successfully contacted Bauer to obtain specific data for this meta-analysis.

\section{Study Selection}

Studies were included if they met the following criteria: participants should be above 18 years old; they focused on the association between statin use and pneumonia; they reported mortality after an episode of pneumonia; and involved overall or adjusted mortality. We excluded studies that reported ventilator-associated pneumonia (cannot distinguish it from severe pneumonia) and did not report the mortality rate after pneumonia.

\section{Data Extraction}

Data were extracted from all included studies independently by Mingwang $\mathrm{Jia}$ and $\mathrm{Li} \mathrm{Li}$. Relevant information of each study include study design, sample demographics (i.e., age, gender), type of statins, type of pneumonia, type of statins, outcome measures, association scale (odds ratio [OR] and adjusted OR), and adjusted confounders. When disagreement appeared between the 2 reviewers, a senior reviewer (Wenjie Huang) was consulted for final decision.

Quality Assessment

We used Newcastle-Ottawa Quality Assessment
Scale (NOS) ${ }^{[21]}$ to assess the quality of observational studies. NOS include three-part: quality of subject selection, comparability between two groups, and reliability of exposure or clinical outcomes. The full score of NOS is 9 and studies were considered of high-quality when scores $\geq 6$. We used Jadad Score ${ }^{[22]}$ to assess the quality of clinical trials. Also, Jadad Score include three-part: randomization, blinding, and withdrawals or dropouts. The full Jadad Score is 5 and studies were considered of high-quality when scores $\geq 3$.

\section{Definition of non-severe/Severe Pneumonia And Exposure/Treatment Groups}

The Infectious Disease Society of America and American Thoracic Society in 2007 issued consensus guidelines on CAP and SCAP (IDSA/ATS 2007) ${ }^{[23]}$. Severe pneumonia group was defined as patients need mechanical ventilation or were in the ICU (requiring vasopressors) in our research. Treatment group was defined as patients taking statins (including prior and current users).

\section{STATISTICAL ANALYSIS}

We performed all statistical analysis using Stata 12.0 software (StataCorp., College Station, TX). We extracted both unadjusted and adjusted OR for pooling both crude and adjusted risk estimates. OR $<1$ indicated that risk of outcome events in the intervention group is lower than that of outcome events in control group, which means that statins reduce mortality of pneumonia. We used $\mathrm{I}^{2}$ statistic to test heterogeneity of the included studies. An $\mathrm{I}^{2}$ value of $25 \%, 50 \%$, and $75 \%$ represents low, moderate, and high heterogeneity, respectively ${ }^{[24]}$. Publication bias was assessed by Begg's test and Egger's test with $P<0.05$ as indicative of publication bias.

We performed sensitivity analysis to test the robustness of our findings. The study design and participants of each study were considered as possible sources of heterogeneity. Meanwhile, we conducted an influence analysis for knowing the specific ones which cause the heterogeneity.

For a better understanding of the influenced confounders for mortality, we performed a subgroup analysis. We took pneumonia severity, propensity score, comorbidity and smoking status as important confounders and analyzed the relationship between confounders and mortality. 


\section{RESULTS}

\section{Studies Included in the Systematic Review}

The database search yielded a total of 512 potential publications during the initial search. And 24 studies involving a total of 312,309 patients ${ }^{[18,25-47]}$ met our inclusion and exclusion criteria (Figure 1). The eligible studies included 2 case-control studies $[28,29], 14$ respective cohort studies $[25,26,31,32,35-38$, 40-44, 46], 5 prospective cohort studies [18, 27, 30, 34, 39] and 3 randomized controlled trials (RCTs) ${ }^{[33,45,47]}$ (Table 1, 2). Sample sizes of included studies ranged from 60 to 121,254 patients. Stratified by study locations, populations in the studies were from Europe, Asia, and North America. Eleven studies reported the types of statins received by population $[18,26,29,30,33,34,42-45,47]$. Eight studies reported in-hospital mortality $[18,26-28,33,36,38,43,46], 1$ reported mortality at 28 days ${ }^{[47]}, 9$ reported 30-day mortality [25, 26, 29-31, 35, 40-42], 2 reported 60-day mortality ${ }^{[39,45]}, 3$ reported 90-day mortality ${ }^{[26,34,44]}$, and 1 reported mortality at 6 months ${ }^{[32]}$. According to our definition of treatment groups, 8 articles ${ }^{[27,33 \text {, }}$ $36,37,39,45-47]$ were classified as severe pneumonia, and the remaining 16 articles $[18,25,26,28-32,34,35,38$, ${ }^{40-44]}$ were non-severe pneumonia.

\section{Non-severe pneumonia Group Unadjusted Mortality}

Of the 24 included studies, 11 studies (2 case control studies, 7 respective cohort studies and 2 prospective cohort studies) reported raw mortality after common pneumonia $[18,25,26,28,29,31,32,34,35,38$, ${ }^{40]}$. Pooled meta-analysis revealed that statin would decrease overall mortality after pneumonia (OR $0.70 ; 95 \%$ confidence interval $[\mathrm{CI}], 0.67-0.73$ ) (Figure 2). A high degree of heterogeneity was observed for the pooled OR of $0.70\left(\mathrm{I}^{2}=77.9 \%, P\right.$ $=0.00)$. However, neither Begg's test $(P=1.00)$ nor Egger's Test $(P=0.18)$ showed evidence of publication bias (Figure 4).

\section{Adjusted Mortality}

Of the 24 included studies, 15 studies (2 case control studies, 10 respective cohort studies and 3 prospective cohort studies) reported adjusted mortality after non-severe pneumonia $[18,25,26,28-32,34$, $35,38,41-44]$. Adjustments included social and demographic factors, pneumonia severity, comorbidity indices, smoking status, vaccination status, and propensity to receive statin treatment. Pooling of these data revealed that statin would decrease overall mortality after pneumonia (OR
0.78; 95\% CI, 0.75-0.82) (Figure 3). A high degree of heterogeneity was observed for the pooled adjusted OR of $0.78\left(\mathrm{I}^{2}=74.3 \%, P=0.001\right)$. Egger's test suggested significant publication bias $(P=0.024)$, but Begg's test did not $(P=0.299)$ (Figure 4).

\section{Severe pneumonia Group Unadjusted Mortality}

Of the 24 included studies, 8 studies $(3$ respective cohort studies, 2 prospective cohort studies and 3 $\mathrm{RCTs}$ ) reported raw mortality after severe

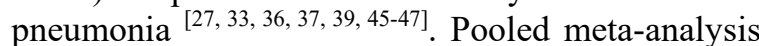
revealed that current statin use was not associated with a decreased of mortality after severe pneumonia (OR 1.05; 95\% CI, 0.86-1.28). A moderate heterogeneity was observed $\left(\mathrm{I}^{2}=41.5 \%\right.$, $P=0.10)$ (Figure 2). Both Begg's test $(P=0.90)$ and Egger's test $(P=0.68)$ suggested no significant publication bias (Figure 4).

\section{Adjusted Mortality}

Of the 24 included studies, 3 studies (1 respective cohort study and 2 prospective cohort studies) reported adjusted mortality after severe pneumonia $[27,36,39]$. Adjustments included social and demographic factors, pneumonia severity, comorbidity indices, smoking status and vaccination status, and propensity to receive statin treatment. Pooling of these data revealed that statin use was not associated with a decrease of mortality after severe pneumonia (OR 0.92; 95\% CI, 0.53-1.60). A moderate heterogeneity was observed $\left(\mathrm{I}^{2}=41.0 \%, P=0.18\right)$ (Figure 3$)$. Both Begg's test $(P=1.00)$ and Egger's test $(P=0.76)$ suggested no significant publication bias (Figure 4).

\section{Subgroup Analysis}

We performed subgroup analysis to determine whether clinical factors influenced the mortality of pneumonia after statins using (Table 3).We took pneumonia severity, propensity score, comorbidity and smoking status as important confounders. In the non-severe pneumonia group, no statistically significant differences were observed. But we found that the protective effect weakened when studies were analyzed according to the inclusion of important confounders in their models, especially the adjusted pooled OR for pneumonia severity $(0.88,95 \%$ CI $0.80-0.96)$ and for propensity score $(0.86,95 \%$ CI $0.80-0.94)$, and the more confounders were considered, the weaker the protective effect was. In the severe pneumonia 


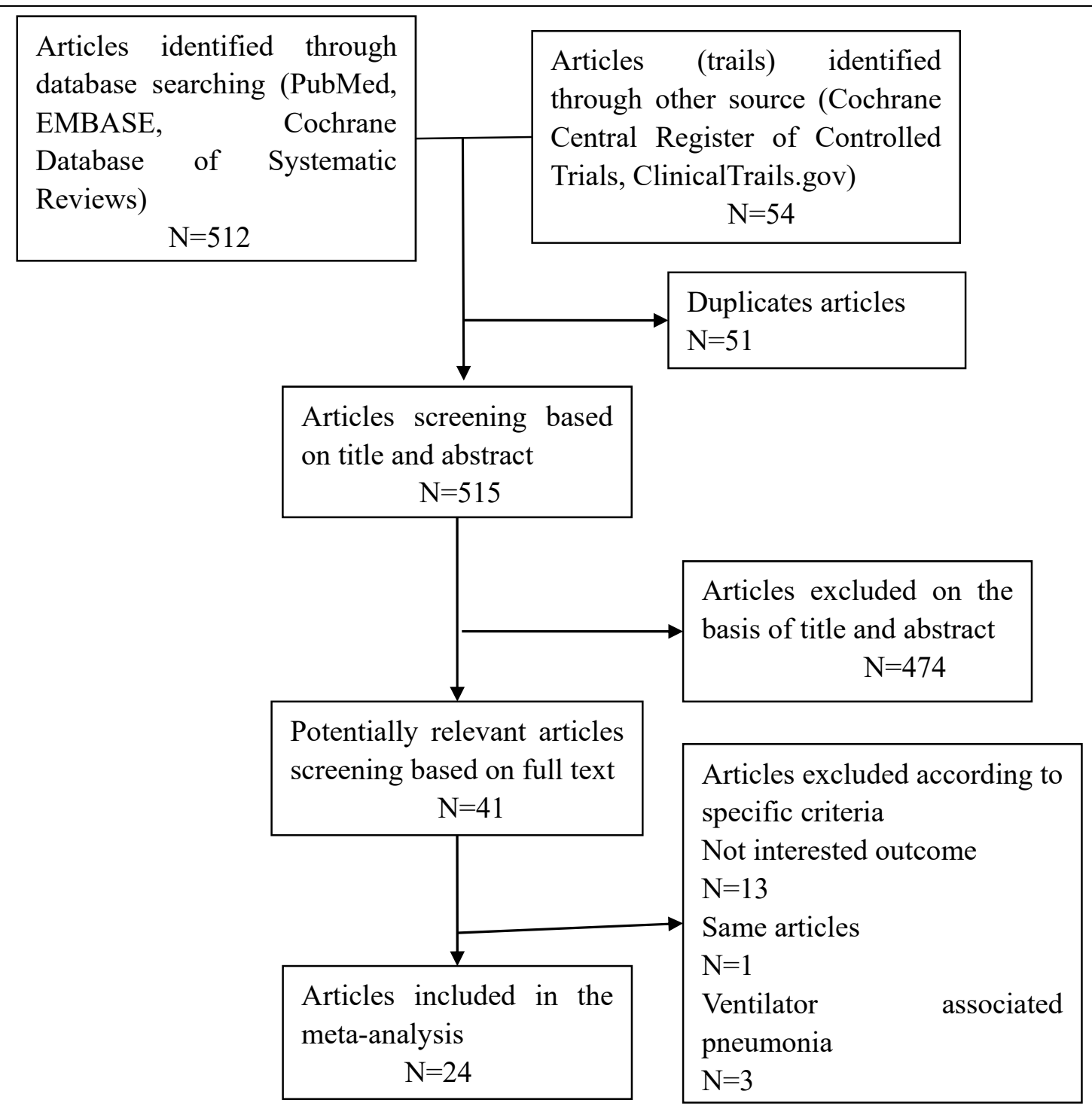

Figure 1. Flowchart of search selection.

group, though OR was lower in the adjusted data, nonetheless, there was no association between statins users and non-statin users.

\section{Sensitivity analysis}

There was a substantial degree of heterogeneity in both unadjusted and adjusted analysis, especially in the non-severe pneumonia group. We performed several sensitivity analyses (Table 4). The $\mathrm{I}^{2}$ statistic was as low as $0 \%$ and $51.5 \%$ for non-severe pneumonia (unadjusted) and non-severe pneumonia (adjusted) in prospective cohorts; 28.6\% and $53.2 \%$ in case-control cohorts, respectively; $0.0 \%$ for severe pneumonia in a RCT. The $\mathrm{I}^{2}$ statistic was as low as $0.0 \%$ for severe pneumonia (unadjusted) in North America, $63.7 \%$ and $0 \%$ for non-severe pneumonia (adjusted) and severe pneumonia (unadjusted) in Europe, respectively. Meanwhile, we performed an influence analysis (Figure 5), which found that, in the unadjusted group, when excluded Kwong's article (only provided the OR value but does not provide a specific number of patients), the $\mathrm{I}^{2}$ statistic changed into moderate heterogeneity $\left(\mathrm{I}^{2}=49.4 \%, P=0.04\right)$ but didn't change result (OR $0.64 ; 95 \% \mathrm{CI}, 0.61-0.68$ ). In the adjusted group, we excluded Kwong and Rothberg's articles. The $\mathrm{I}^{2}$ statistic changed to moderate heterogeneity $\left(\mathrm{I}^{2}=41.1 \%, P=0.06\right)$ but didn't change result (OR 0.69; 95\% CI, 0.65-0.74). 


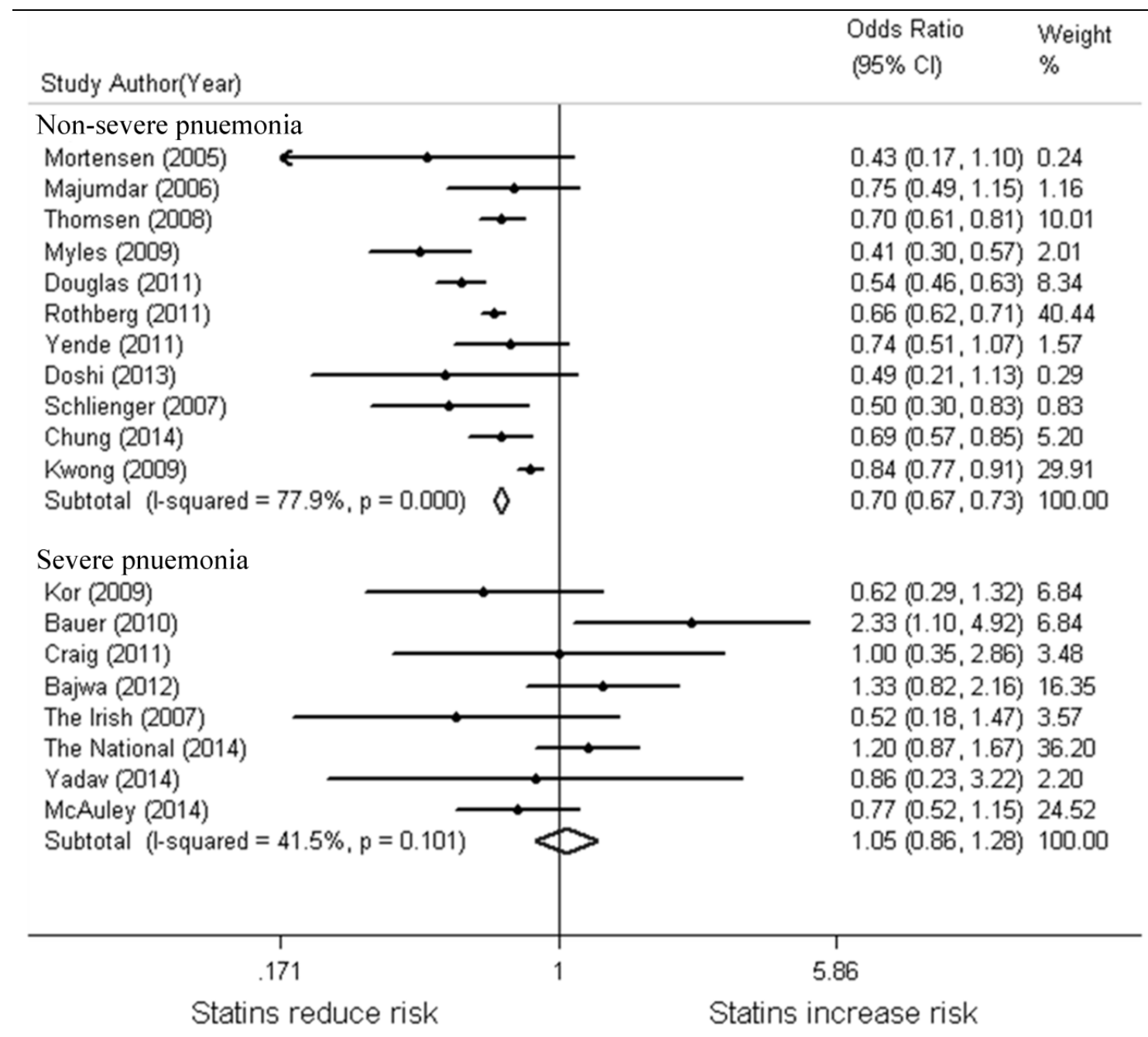

Figure 2. Forest for the pooled unadjusted association between statin use and mortality. Forest plot showed that statin users were less likely to die after an episode of non-severe pneumonia compared with nonstatin users in unadjusted estimates, but in the severe pneumonia group, there was no obvious difference in mortality.

\section{DISCUSSION}

This meta-analysis of 24 studies showed that statin users were less likely to die after non-severe pneumonia compared with non-statin users, but in the severe pneumonia group, there was no obvious difference in mortality. In the non-severe pneumonia group, statins was associated with reduced mortality using both unadjusted and adjusted estimates. However, this protective effect was weakened in subgroups.

In non-severe pneumonia group, statin reduced the mortality using adjusted and unadjusted estimates but there was no association in severe pneumonia group using either adjusted estimates or unadjusted estimates. Kwok's meta-analysis did not find an association between pneumonia and statins using unadjusted data but found an association using adjusted data ${ }^{[48]}$. Chopra's meta-analysis found an association between pneumonia and statins using both unadjusted data and adjusted data ${ }^{[49]}$. These results suggested the severity should be considered when using statin for pneumonia treatment. In a subgroup analysis, we obtained similar results to Chopra ${ }^{[49]}$. 


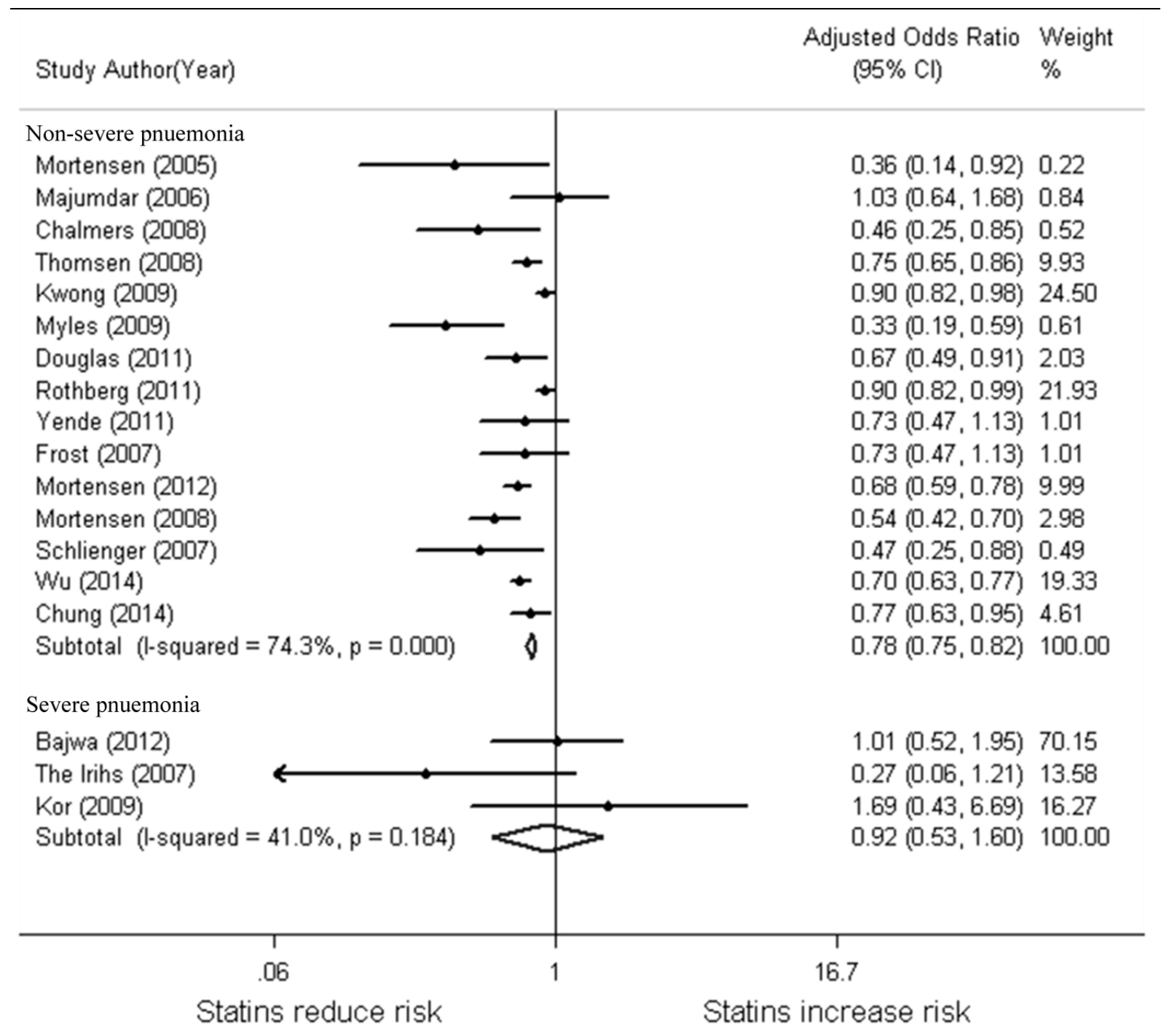

Figure 3. Forest for the pooled adjusted association between statin use and mortality. Forest plot showed that protective effect of statins was weakened in non-severe pneumonia when accounting for adjusted estimates, and there was no obvious difference in mortality in adjusted severe pneumonia group.

The protective effect we found was weakened when accounting for patient differences through the use of propensity scores, pneumonia severity indicators, smoking status and comorbidity in non-severe pneumonia group.

There were several limitations for this Systematic Review and Meta-analysis. First, the definition of severe pneumonia has flaws. We define patients who need mechanical ventilation or in the ICU (requiring vasopressors) as the severe pneumonia group in our research, and we may have missed severe pneumonia patients who did not use mechanical ventilation or vasopressors or did not mention these parameters in the papers. Additionally, not all ALI/ARDS were caused by pneumonia. However, considering that pneumonia is the main reason of ALI/ARDS and that there must be lung inflammation after developing ALI/ARDS, we define ALI/ARDS as severe pneumonia in our paper. Second, few papers discussed the adjusted OR in severe pneumonia, which may lead to an obvious bias. Thus, we performed a subgroup analysis and analyzed an unadjusted group for better understanding of severe pneumonia. 
A

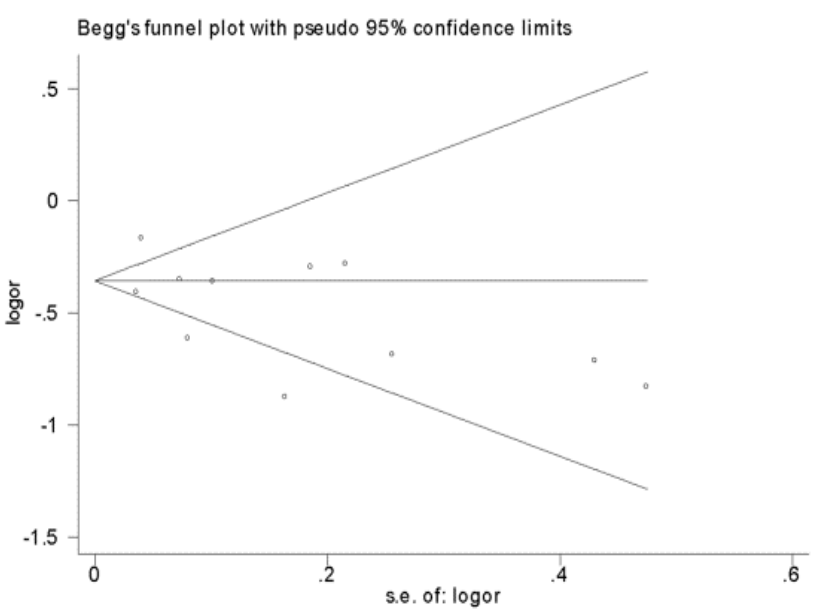

C

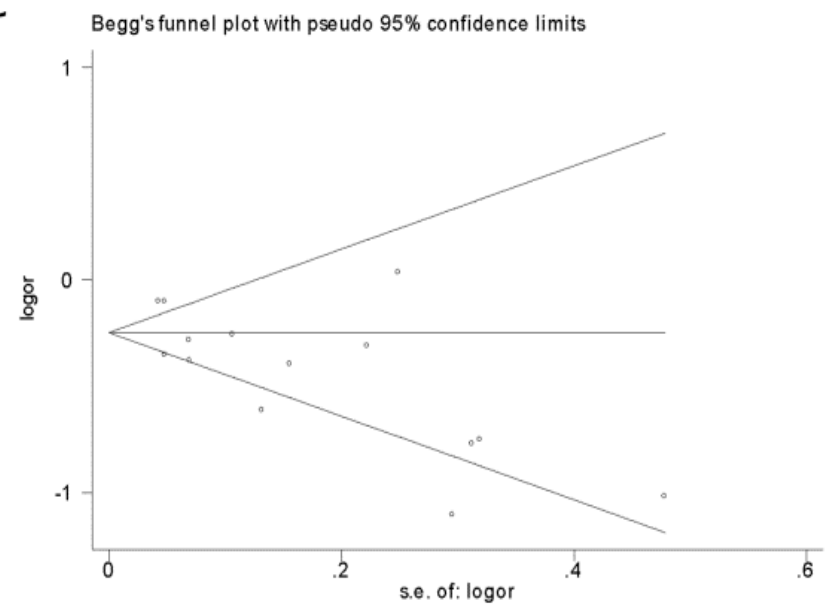

B

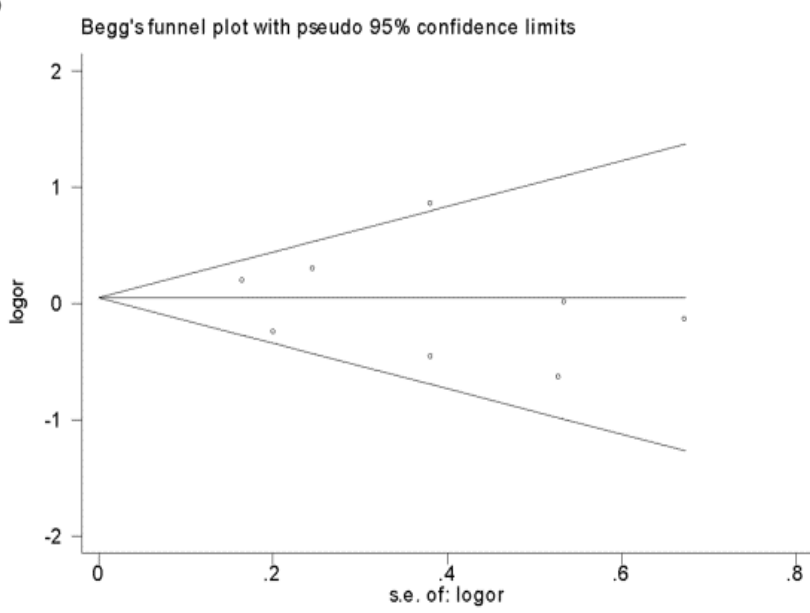

D

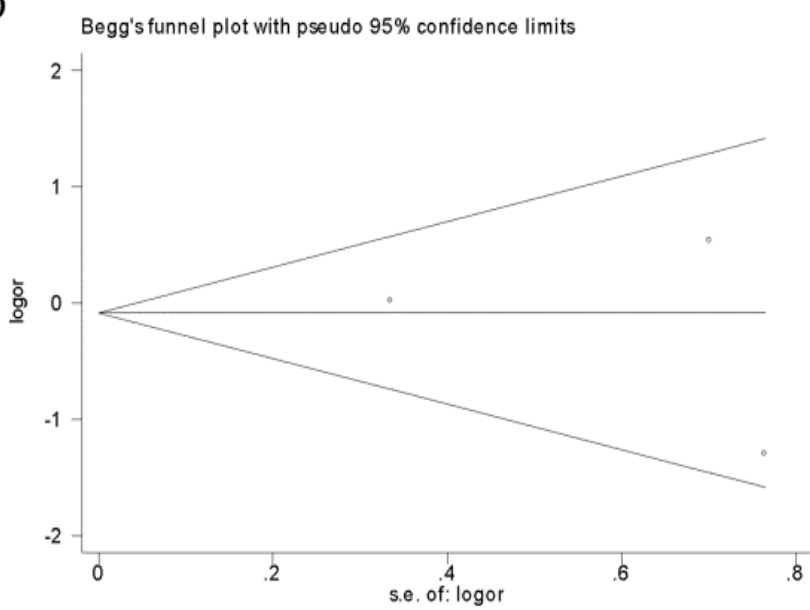

Figure 4. Begg's test for Publication bias. Begg's test for unadjusted non-severe pneumonia (A), unadjusted severe pneumonia (B), adjusted non-severe pneumonia (C) and adjusted severe pneumonia (D).

Third, although we conducted adjusted measures and performed subgroup analysis, residual confounding and healthy-user bias remain threats to our conclusions. However, our analysis has important strengths. We divided pneumonia into non-severe pneumonia and severe pneumonia and performed a subgroup analysis to determine whether methodological or clinical factors influenced the meta-analytical estimates of statins on pneumonia mortality.

Statin use is associated with a reduction in mortality in non-severe pneumonia, but because this association in attenuated in studies with a better adjustment for confounders, it is likely that this association is at least partly explained by a healthy user effect. The protective effect of statin was weakened in a subgroup analysis by confounders in non-severe pneumonia, especially when accounting for patient differences through the use of pneumonia severity indicators. In future work, a double-blind, randomized, large sample experiment is necessary considering pneumonia severity as an important element.

\section{FUNDING SOURCE}

No sponsorship from institutions or pharmaceutical industry was provided to conduct this study. 
A

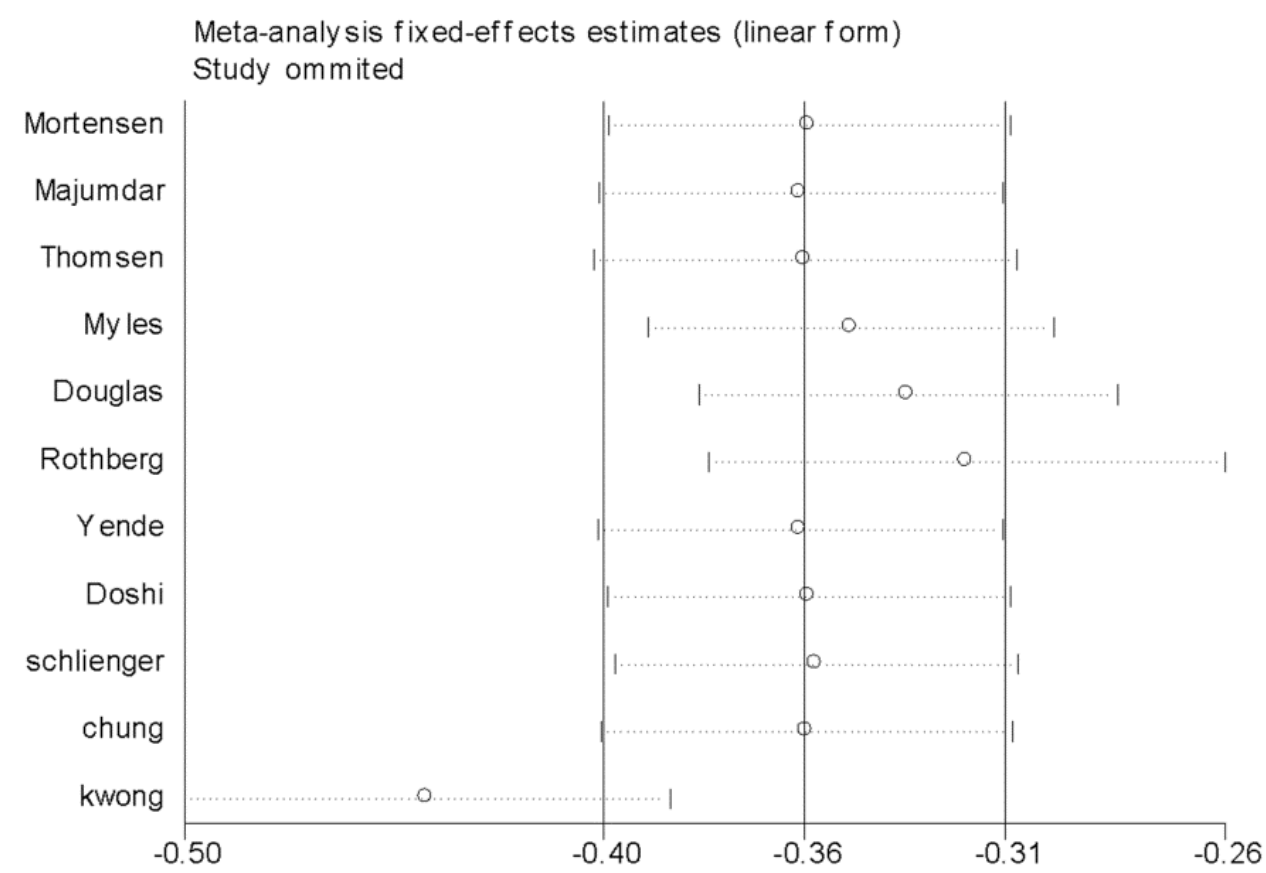

B

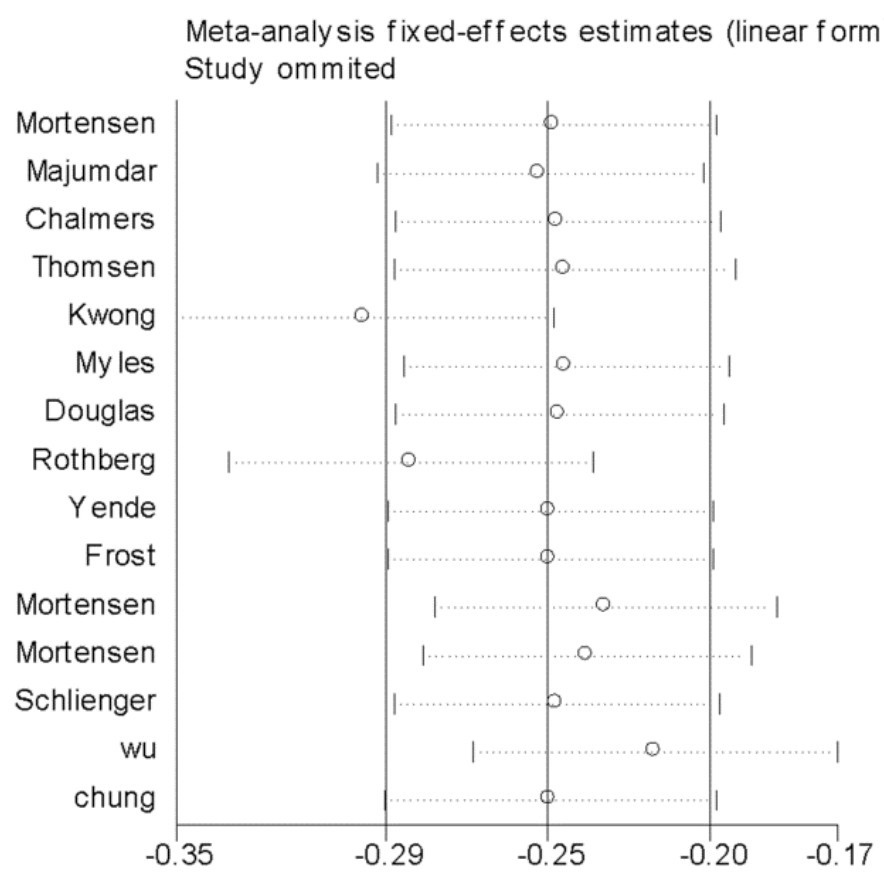

Figure 5. Sensitivity analysis for unadjusted non-severe pneumonia (A) and adjusted non-severe pneumonia (B).

\section{REFERENCES}

1. W.I. Sligl and T.J. Marrie. Severe community-acquired pneumonia. Critical Care Clinics 29(3): 563-601, 2013.
2. M.L. Jackson, et al. The burden of community-acquired pneumonia in seniors: results of a population-based study. Clinical Infectious 
Diseases 39(11): 1642-1650, 2004.

3. S.L. Murphy, J. Xu, and K.D. Kochanek. Deaths: final data for 2010. National vital statistics reports: from the Centers for Disease Control and Prevention, National Center for Health Statistics, National Vital Statistics System 61(4): 1-117, 2013.

4. V.C. Buie, et al. National Hospital Discharge Survey: 2006 Annual Summary. Vital and health statistics. Series 13, Data from the National Health Survey (168): 1-79, 2010.

5. M.J. Hall, S. Levant, and C.J. DeFrances. Trends in inpatient hospital deaths: National Hospital Discharge Survey, 2000-2010. 2013: Citeseer.

6. M.M. Bonafede, et al. Incidence and cost of CAP in a large working-age population. The American journal of managed care 18(7): 380-387, 2012.

7. M.S. Niederman, et al. Guidelines for the management of adults with community-acquired pneumonia: diagnosis, assessment of severity, antimicrobial therapy, and prevention. American journal of respiratory and critical care medicine 163(7): 1730-1754, 2001.

8. D. Viasus, et al. Statins for community-acquired pneumonia: current state of the science. European journal of clinical microbiology \& infectious diseases 29(2): 143-152, 2010.

9. H. Schuster, et al. Effects of switching statins on achievement of lipid goals: Measuring Effective Reductions in Cholesterol Using Rosuvastatin Therapy (MERCURY I) study. American heart journal 147(4): 705-712, 2004.

10. S.E. Nissen, et al. Statin therapy, LDL cholesterol, C-reactive protein, and coronary artery disease. New England Journal of Medicine 352(1): 29-38, 2005.

11. K.M. Gowdy and M.B. Fessler. Emerging roles for cholesterol and lipoproteins in lung disease. Pulmonary pharmacology \& therapeutics 26(4): 430-437, 2013.

12. J.D. Chalmers, et al. Statins in community acquired pneumonia: Evidence from experimental and clinical studies. Respiratory medicine 104(8): 1081-1091, 2010.

13. A. Liappis, et al. The effect of statins on mortality in patients with bacteremia. Clinical Infectious Diseases 33(8): 1352-1357, 2001.

14. L. Björkhem-Bergman, et al. Statin treatment and mortality in bacterial infections-a systematic review and meta-analysis. PloS one 5(5): e10702, 2010.

15. S. Janda, et al. The effect of statins on mortality from severe infections and sepsis: a systematic review and meta-analysis. Journal of critical care 25(4): 656. e7-656. e22, 2010.

16. I.M. Tleyjeh, et al. Statins for the prevention and treatment of infections: a systematic review and meta-analysis. Archives of internal medicine 169(18): 1658-1667, 2009.

17. R. Fernandez, V.J. De Pedro, and A. Artigas. Statin therapy prior to ICU admission: protection against infection or a severity marker? Intensive care medicine 32(1): 160-164, 2006.

18. S.R. Majumdar, et al. Statins and outcomes in patients admitted to hospital with community acquired pneumonia: population based prospective cohort study. Bmj 333(7576): 999, 2006.

19. D. Moher, et al. Preferred reporting items for systematic reviews and meta-analyses: the PRISMA statement. International Journal of Surgery 8(5): 336-341, 2010.

20. D.F. Stroup, et al. Meta-analysis of observational studies in epidemiology: a proposal for reporting. Jama 283(15): 2008-2012, 2000.

21. G. Wells, et al. The Newcastle-Ottawa Scale (NOS) for assessing the quality of nonrandomised studies in meta-analyses. 2000.

22. A.R. Jadad, et al. Assessing the quality of reports of randomized clinical trials: is blinding necessary? Controlled clinical trials 17(1): 1-12, 1996.

23. L.A. Mandell, et al. Infectious Diseases Society of America/American Thoracic Society consensus guidelines on the management of community-acquired pneumonia in adults. Clinical Infectious Diseases 44(Supplement 2): S27-S72, 2007.

24. J.P. Higgins, et al. Measuring inconsistency in meta-analyses. BMJ: British Medical Journal 327(7414): 557, 2003.

25. J.C. Kwong, P. Li, and D.A. Redelmeier. Influenza morbidity and mortality in elderly patients receiving statins: a cohort study. PloS one 4(11): e8087, 2009.

26. R.W. Thomsen, et al. Preadmission use of statins and outcomes after hospitalization with pneumonia: population-based cohort study of 29900 patients. Archives of internal medicine 168(19): 2081-2087, 2008.

27. I.C.C.T. Group. Acute lung injury and the acute respiratory distress syndrome in Ireland: a prospective audit of epidemiology and management. Critical care 12(1): R30, 2008.

28. S.D. Chung, et al. Statin use and clinical outcomes among pneumonia patients. Clinical Microbiology and Infection 20(9): 879-885, 2014.

29. R.G. Schlienger, et al. Statins and the risk of pneumonia: a population-based, nested case-control study. Pharmacotherapy: The Journal of Human Pharmacology and Drug Therapy 27(3): 325-332, 2007.

30. J.D. Chalmers, et al. Prior statin use is associated with improved outcomes in community-acquired pneumonia. The American journal of medicine 121(11): 1002-1007. e1, 2008.

31. P.R. Myles, et al. The impact of statins, ACE inhibitors and gastric acid suppressants on pneumonia mortality in a UK general practice population cohort. Pharmacoepidemiology and drug 
safety 18(8): 697-703, 2009.

32. I. Douglas, S. Evans, and L. Smeeth. Effect of statin treatment on short term mortality after pneumonia episode: cohort study. Bmj 3422011.

33. T.R. Craig, et al. A randomized clinical trial of hydroxymethylglutaryl-coenzyme a reductase inhibition for acute lung injury (the HARP study). American journal of respiratory and critical care medicine 183(5): 620-626, 2011.

34. S. Yende, et al. Understanding the potential role of statins in pneumonia and sepsis. Critical care medicine 39(8): 1871, 2011.

35. E.M. Mortensen, et al. The effect of prior statin use on 30-day mortality for patients hospitalized with community-acquired pneumonia. Respiratory research 6(1): 82, 2005.

36. D.J. Kor, et al. Statin administration did not influence the progression of lung injury or associated organ failures in a cohort of patients with acute lung injury. Intensive care medicine 35(6): 1039-1046, 2009.

37. S. Bauer, S. Lam, and A. Reddy. Effect of statin therapy on outcomes in patients with acute lung injury and acute respiratory distress syndrome. American journal of respiratory and critical care medicine 1812010.

38. M.B. Rothberg, et al. Association between statins given in hospital and mortality in pneumonia patients. Journal of general internal medicine 27(3): 280-286, 2012.

39. E.K. Bajwa, et al. Statin therapy as prevention against development of acute respiratory distress syndrome: an observational study. Critical care medicine 40(5): 1470, 2012.

40. S.M. Doshi, et al. The impact of statin and macrolide use on early survival in patients with pneumococcal pneumonia. The American journal of the medical sciences 345(3): 173-177, 2013.
41. F.J. Frost, et al. Influenza and COPD mortality protection as pleiotropic, dose-dependent effects of statins. CHEST Journal 131(4): 1006-1012, 2007.

42. E.M. Mortensen, et al. Population-based study of statins, angiotensin II receptor blockers, and angiotensin-converting enzyme inhibitors on pneumonia-related outcomes. Clinical Infectious Diseases 55(11): 1466-1473, 2012.

43. E. Mortensen, et al. Impact of statins and angiotensin-converting enzyme inhibitors on mortality of subjects hospitalised with pneumonia. European Respiratory Journal 31(3): 611-617, 2008.

44. A. $\mathrm{Wu}$, et al. The association of cardioprotective medications with pneumonia-related outcomes. PloS one 9(1): e85797, 2014.

45. T.N. Heart. Rosuvastatin for sepsis-associated acute respiratory distress syndrome. The New England journal of medicine 370(23): 2191, 2014.

46. H. Yadav, et al. Preoperative Statin Administration Does Not Protect Against Early Postoperative Acute Respiratory Distress Syndrome: A Retrospective Cohort Study. Anesthesia \& Analgesia 119(4): 891-898, 2014

47. D.F. McAuley, et al. Simvastatin in the acute respiratory distress syndrome. New England Journal of Medicine 371(18): 1695-1703, 2014.

48. C.S. Kwok, et al. Statins and associated risk of pneumonia: a systematic review and meta-analysis of observational studies. European journal of clinical pharmacology 68(5): 747-755, 2012.

49. V. Chopra, et al. Is statin use associated with reduced mortality after pneumonia? A systematic review and meta-analysis. The American journal of medicine 125(11): 1111-1123, 2012. 


\begin{tabular}{|c|c|c|c|c|c|c|c|c|}
\hline \multirow{2}{*}{ Study (First author; year) } & \multirow{2}{*}{ Country } & \multirow{2}{*}{$\begin{array}{l}\text { Study } \\
\text { Design }\end{array}$} & \multirow{2}{*}{$\begin{array}{l}\text { Mean } \\
\text { Age } \\
(Y)\end{array}$} & \multirow{2}{*}{$\begin{array}{l}\% \\
\text { Male }\end{array}$} & \multirow{2}{*}{ Statin Type(s) } & \multicolumn{3}{|c|}{ Sample Size (n) } \\
\hline & & & & & & Statin & Nonstatin & Total \\
\hline Majumdar; $2006^{[18]}$ & Canada & $\mathrm{PC}$ & 75 & 53 & $\begin{array}{l}\text { Simvastatin, Pravastatin, } \\
\text { Atorvastatin accounted for } 90 \%\end{array}$ & 325 & 3,090 & 3,415 \\
\hline Kwong; $2009^{[25]}$ & Canada & $\mathrm{RC}$ & 74 & 45 & Not reported & N/A & N/A & 13,027 \\
\hline Thomsen; $2008^{[26]}$ & Denmark & $\mathrm{RC}$ & 73 & 53 & $\begin{array}{l}\text { Simvastatin( } 61 \%), \text { Pravastatin( } 15 \%) \text {, } \\
\text { Atorvastatin(15\%),other( } 9 \%)\end{array}$ & 1,372 & 285,28 & 29,900 \\
\hline $\begin{array}{l}\text { The Irish Critical Care Trials Group; } \\
2007^{[27]}\end{array}$ & Ireland & $\mathrm{PC}$ & 58 & 62 & Not reported & 24 & 164 & 188 \\
\hline Chung; 2014 [28] & Taiwan & $\mathrm{CC}$ & N/A & 53.7 & Not reported & 2,894 & 8,682 & 11,576 \\
\hline Schlienger; $2007^{[29]}$ & $\begin{array}{l}\text { United } \\
\text { Kingdom }\end{array}$ & $\mathrm{CC}$ & N/A & 54.4 & $\begin{array}{l}\text { atorvastatin, fluvastatin, lovastatin, } \\
\text { pravastatin, or simvastatin }\end{array}$ & 141 & 1,112 & 1,253 \\
\hline Chalmers; $2008^{[30]}$ & $\begin{array}{l}\text { United } \\
\text { Kingdom }\end{array}$ & $\mathrm{PC}$ & 66 & 49.7 & $\begin{array}{l}\operatorname{Simvastatin}(72 \%), \text { Atorvastatin }(21.4 \%) \text {, } \\
\text { Pravastatin }(6.6 \%)\end{array}$ & 257 & 750 & 1,007 \\
\hline Myles; $2009^{[31]}$ & $\begin{array}{l}\text { United } \\
\text { Kingdom }\end{array}$ & $\mathrm{RC}$ & N/A & N/A & Not reported & 357 & 3,324 & 3,681 \\
\hline Douglas; $2011^{[32]}$ & $\begin{array}{l}\text { United } \\
\text { Kingdom }\end{array}$ & $\mathrm{RC}$ & N/A & N/A & Not reported & 1,789 & 6,542 & 8,331 \\
\hline
\end{tabular}


J Pharm Pharm Sci (www.cspsCanada.org) 18(3) 286 - 302, 2015

Table 1 continued...

\begin{tabular}{|c|c|c|c|c|c|c|c|c|}
\hline Craig; $2011^{[33]}$ & $\begin{array}{l}\text { United } \\
\text { Kingdom }\end{array}$ & $\mathrm{RCT}$ & 52.3 & 73 & simvastatin & 30 & 30 & 60 \\
\hline Yende; $2011^{[34]}$ & $\begin{array}{l}\text { United } \\
\text { States }\end{array}$ & $\mathrm{PC}$ & 68.8 & 53 & $\begin{array}{l}\text { Atorvastatin( }(47.7 \%), \text { Simvastatin(39.4\%), } \\
\text { Pravastatin(7.7\%), Lovastatin(3.5\%), } \\
\text { Fluvastatin(1.6\%) }\end{array}$ & 426 & 1,469 & 1,895 \\
\hline Mortensen; $2005^{[35]}$ & $\begin{array}{l}\text { United } \\
\text { States }\end{array}$ & $\mathrm{RC}$ & 60 & 79 & Not reported & 110 & 677 & 787 \\
\hline Kor; $2009^{[36]}$ & $\begin{array}{l}\text { United } \\
\text { States }\end{array}$ & $\mathrm{RC}$ & 64.8 & 51.7 & Not reported & 45 & 133 & 178 \\
\hline Bauer; $2010^{[37]}$ & $\begin{array}{l}\text { United } \\
\text { States }\end{array}$ & $\mathrm{RC}$ & 57.6 & 46.5 & Not reported & 37 & 150 & 187 \\
\hline Rothberg; $2011^{[38]}$ & $\begin{array}{l}\text { United } \\
\text { States }\end{array}$ & $\mathrm{RC}$ & 74 & 44 & Not reported & 23,285 & 97,969 & 121,254 \\
\hline Bajwa; $2012^{[39]}$ & $\begin{array}{l}\text { United } \\
\text { States }\end{array}$ & $\mathrm{PC}$ & 59.7 & 62 & Not reported & 75 & 663 & 738 \\
\hline Doshi; $2013^{[40]}$ & $\begin{array}{l}\text { United } \\
\text { States }\end{array}$ & $\mathrm{RC}$ & 64.3 & N/A & Not reported & 90 & 257 & 347 \\
\hline Frost; $2007^{[41]}$ & $\begin{array}{l}\text { United } \\
\text { States }\end{array}$ & $\mathrm{RC}$ & N/A & N/A & Not reported & 19,058 & 57,174 & 76,232 \\
\hline Mortensen; $2012^{[42]}$ & $\begin{array}{l}\text { United } \\
\text { States }\end{array}$ & $\mathrm{RC}$ & 74.8 & 98.2 & $\begin{array}{l}\text { atorvastatin, cerivastatin,fluvastatin, } \\
\text { lovastatin, pravastatin, simvastatin }\end{array}$ & 7,763 & 15,233 & 22,996 \\
\hline Mortensen; $2008^{[43]}$ & $\begin{array}{l}\text { United } \\
\text { States }\end{array}$ & $\mathrm{RC}$ & 75.2 & 98.6 & $\begin{array}{l}\text { atorvastatin, cerivastatin, fluvastatin, } \\
\text { lovastatin, pravastatin, simvastatin }\end{array}$ & 1,567 & 7,085 & 8,652 \\
\hline $\mathrm{Wu} ; 2014^{[44]}$ & $\begin{array}{l}\text { United } \\
\text { States }\end{array}$ & $\mathrm{RC}$ & 74.6 & N/A & $\begin{array}{l}\text { atorvastatin, cerivastatin, fluvastatin, } \\
\text { lovastatin, pravastatin, and simvastatin }\end{array}$ & N/A & N/A & 5,301 \\
\hline $\begin{array}{l}\text { The National Heart, Lung and Blood } \\
\text { Institute; } 2014 \text { [45] }\end{array}$ & $\begin{array}{l}\text { United } \\
\text { States }\end{array}$ & RCT & 52.4 & 49 & rosuvastatin & 379 & 366 & 745 \\
\hline
\end{tabular}


J Pharm Pharm Sci (www.cspsCanada.org) 18(3) 286 - 302, 2015

Table 1 continued...

\begin{tabular}{|c|c|c|c|c|c|c|c|c|}
\hline Yadav; $2014{ }^{[46]}$ & $\begin{array}{l}\text { United } \\
\text { States }\end{array}$ & $\mathrm{RC}$ & 67.9 & 66 & Not reported & 52 & 68 & 120 \\
\hline McAuley; 2014 [47] & $\begin{array}{l}\text { United } \\
\text { Kingdom }\end{array}$ & $\mathrm{RCT}$ & 53.8 & 57 & simvastatin & 259 & 280 & 539 \\
\hline
\end{tabular}

$\mathrm{OR}=$ odds ratio $\mathrm{PC}=$ prospective cohort $\mathrm{RC}=$ retrospective cohort $\mathrm{RCT}=$ randomized controlled trial; $\mathrm{CC}=$ case-control; $\mathrm{N} / \mathrm{A}=$ not available

\begin{tabular}{|c|c|c|c|c|c|c|}
\hline $\begin{array}{l}\text { Study } \quad \text { (First author; } \\
\text { year) }\end{array}$ & $\begin{array}{l}\text { Key Variables Adjusted in } \\
\text { Regression Models }\end{array}$ & Clinical Outcomes & OR (95\% CI) & $\begin{array}{l}\text { Adjusted OR } \\
\text { CI) }\end{array}$ & $(95 \%$ & $\begin{array}{l}\text { Quality } \\
\text { score }\end{array}$ \\
\hline Majumdar; $2006^{[18]}$ & 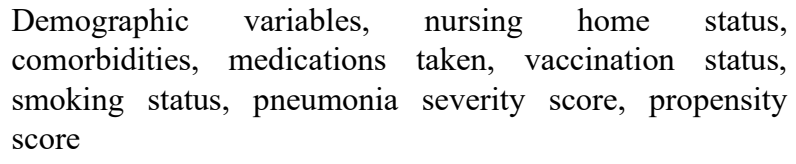 & In-hospital mortality & $0.75(0.49-1.15)$ & $1.03(0.64-1.68)$ & & 6 \\
\hline Kwong; $2009^{[25]}$ & $\begin{array}{l}\text { Demographic variables, hospitalizations in the past three } \\
\text { years, current medications prescribed, influenza-related } \\
\text { risk factors, type of statin prescribed }\end{array}$ & 30-day mortality & $0.84(0.77-0.91)$ & $0.9(0.82-0.98)$ & & 7 \\
\hline Thomsen; $2008^{[26]}$ & $\begin{array}{l}\text { Demographic variables, comorbidity, alcoholism-related } \\
\text { disorders, urbanization of place of residence, type of } \\
\text { hospital, current medications prescribed, calendar period }\end{array}$ & $\begin{array}{l}\text { 30-day mortality, } \\
\text { 90-day mortality }\end{array}$ & $0.70(0.61-0.81)$ & $0.75(0.65-0.86)$ & & 8 \\
\hline $\begin{array}{l}\text { The Irish Critical Care } \\
\text { Trials Group; } 2007^{[27]}\end{array}$ & $\begin{array}{l}\text { Demographic variables, SOFA score, } \mathrm{PaO} 2 / \mathrm{FiO} 2 \text { ratio, } \\
\text { plateau pressure, } \mathrm{Vt} / \mathrm{kg} \text {, arterial carbon dioxide tension and } \\
\text { use of statins }\end{array}$ & In-hospital mortality & $0.52(0.18-1.47)$ & $0.27(0.06-1.21)$ & & 7 \\
\hline Chung; $20144^{[28]}$ & $\begin{array}{l}\text { Demographic variables, CCI score, propensity score, } \\
\text { monthly income, residential urbanization and residential } \\
\text { region }\end{array}$ & In-hospital mortality & $0.69(0.57-0.85)$ & $0.77(0.63-0.95)$ & & 7 \\
\hline Schlienger; $2007^{[29]}$ & $\begin{array}{l}\text { Smoking status, body mass index, influenza or } \\
\text { pneumococcal vaccination, current medications prescribed, } \\
\text { chronic comorbid conditions }\end{array}$ & 30-day mortality & $0.50(0.30-0.83)$ & $0.47(0.25-0.88)$ & & 6 \\
\hline
\end{tabular}


Table 2 continued...

Chalmers; $2008^{[30]}$

Myles; $2009^{[31]}$

Douglas; $2011^{[32]}$

Craig; $2011^{[33]}$

Yende; $2011^{[34]}$

Mortensen; $2005^{[35}$

Kor; $2009^{[36]}$

Bauer; $2010^{[37]}$

Rothberg; $2011^{[38]}$

Bajwa; $2012^{[39]}$

Doshi; $2013^{[40]}$
Age, pneumonia severity score; comorbidity, smoking, aspirin, $\beta$-blockers, ACE inhibitor use

Demographic variables, current smoking ,socio-economic status, comorbidity

Demographic variables, propensity score(body mass index, socioeconomic status, consultation rate, prescribing rate, smoking status, etc.

\section{RCT}

Demographics and comorbidities, severity of illness, treatments received, healthy user indicators

Propensity score, use of statin at presentation, process of care measures

Statin administration, propensity score, APACHE III predicted ICU LOS, DNR code status on admission to the ICU, and postoperative state

Statin group, gender, and fluid balance during ARDS episode, use of corticosteroids, propensity score, age, APACHE II score, and tidal volume

Demographic variables, comorbidities, early non-pneumonia treatments, physician specialty, medications associated with statin use, severity of pneumonia, propensity scores

Demographic variables, severity of illness, vasopressor or corticosteroid use, presence of shock, liver or renal failure, history of diabetes, aspirin, propensity score

Age, sex and preexisting conditions and alcohol use, disease severity scores 30-day mortality

N/A

$0.46(0.25-0.85)$

30-day mortality

$0.41(0.30-0.57)$

$0.33(0.19-0.59)$

6-month mortality $\quad 0.54(0.46-0.63) \quad 0.67(0.49-0.91)$

ICU mortality,

Hospital mortality

90-day mortality

$0.74(0.51-1.07)$

$.73(0.47-1.13)$

30-day mortality

$0.43(0.17-1.10)$

$0.36(0.14-0.92)$

7

ICU mortality, Hospital mortality

$0.62(0.29-1.32) \quad 1.69(0.43-6.69)$

7

ICU mortality

$2.33(1.10-4.92)$

$\mathrm{N} / \mathrm{A}$

In-hospital mortality $\quad 0.66(0.62-0.71) \quad 0.90(0.82-0.99)$

6

60-day mortality

$1.33(0.82-2.16)$

$1.01(0.52-1.95)$

9

30-day mortality

$0.49(0.21-1.13)$

N/A 


\section{Table 2 continued...}

Frost; 2007 [41]

Mortensen; $2012^{[42]}$

Mortensen; $2008^{[43]}$

$\mathrm{Wu} ; 2014^{[44]}$

The National Heart, Lung and Blood Institute; 2014 RCT

[45]

Yadav; $2014^{[46]}$

McAuley; $2014{ }^{[47]}$
Duration of enrollment before initiation of statin therapy, the CCI, the number of different medications taken, receiving influenza vaccinations after initiation of statin therapy.

Demographic variables, receipt of guideline concordant antibiotics, comorbid conditions, other medications.

30-day mortality

$\mathrm{N} / \mathrm{A}$

Demographic variables, VA means test, classes of medications and the Charlson composite score

In-hospital mortality N/A

$0.54(0.42-0.70)$

8

Demographics, intensive care unit admission, need for mechanical ventilation and/or vasopressors, prior comorbid conditions, and other outpatient medications.

Demographic variables, comorbidities, treatments received; smoking, alcohol abuse, BMI, other In-hospital mortality $0.86(0.23-3.22) \quad \mathrm{N} / \mathrm{A}$ medications.

\section{RCT}

N/A, not available

\begin{tabular}{|c|c|c|c|c|}
\hline \multirow[b]{2}{*}{ Subgroup } & \multicolumn{2}{|c|}{ Non-severe pneumonia OR (95\% CI) } & \multicolumn{2}{|c|}{ Severe pneumonia OR (95\% CI) } \\
\hline & Unadjusted Data & Adjusted Data & Unadjusted Data & Adjusted Data \\
\hline Adjustment for pneumonia severity & $0.67(0.62-0.71)^{[18,34,35,38,40]}$ & $0.88(0.80-0.96)^{[18,30,34,35,38]}$ & $1.33(0.82-2.16)^{[39]}$ & $1.01(0.52-1.95)^{[39]}$ \\
\hline
\end{tabular}


J Pharm Pharm Sci (www.cspsCanada.org) 18(3) 286 - 302, 2015

\begin{tabular}{|c|c|c|c|c|}
\hline Adjustment for propensity score & $0.65(0.61-0.69)^{[18,28,32,38]}$ & $0.86(0.80-0.94)^{[18,28,32,38]}$ & $1.25(0.88-1.77)^{[36,37,39]}$ & $1.11(0.61-2.02)^{[36,39]}$ \\
\hline Adjustment for comorbidity & $0.66(0.62-0.70)^{[18,26,28,29,31,34,38]}$ & $0.76(0.72-0.80)^{[18,26,28-31,34,38,42,44]}$ & N/A & N/A \\
\hline Adjustment for smoking status & $0.55(0.48-0.62)^{[18,29,31,32,34]}$ & $0.65(0.53-0.79)^{[18,29-32,34]}$ & $\mathrm{N} / \mathrm{A}$ & N/A \\
\hline One confounder & $0.69(0.60-0.79)^{[26,35,40]}$ & $0.70(0.66-0.76)^{[26,35,42,44]}$ & $1.20(0.71-2.05)^{[36,37]}$ & $1.69(0.43-6.69)^{[36]}$ \\
\hline Two confounders & $0.51(0.45-0.59)^{[29,31,32]}$ & $0.55(0.43-0.71)^{[29,31,32]}$ & $1.33(0.82-2.16)^{[39]}$ & $1.01(0.52-1.95)^{[39]}$ \\
\hline Three confounders & $0.67(0.62-0.71)^{[34,38]}$ & $0.88(0.80-0.96)^{[30,34,38]}$ & $\mathrm{N} / \mathrm{A}$ & N/A \\
\hline Four confounders & $0.75(0.49-1.15)^{[18]}$ & $1.03(0.64-1.08)^{[18]}$ & $\mathrm{N} / \mathrm{A}$ & $\mathrm{N} / \mathrm{A}$ \\
\hline
\end{tabular}

$\mathrm{CI}=$ confidence interval; $\mathrm{OR}=$ odds ratio; $\mathrm{N} / \mathrm{A}=$ not available.

\begin{tabular}{|c|c|c|c|c|}
\hline \multirow[b]{2}{*}{ Subgroup } & \multicolumn{2}{|l|}{ Non-severe pneumonia OR $(95 \% \mathrm{CI}) \mathrm{I}^{2}$} & \multicolumn{2}{|c|}{ Severe pneumonia OR $\left(95 \%\right.$ CI) $I^{2}$} \\
\hline & Unadjusted Data & Adjusted Data & Unadjusted Data & Adjusted Data \\
\hline \multicolumn{5}{|l|}{ Study design } \\
\hline Retrospective cohort & $0.69(0.66-0.73) 86.7 \% 0^{[25,26,31,32,35,38,40]}$ & 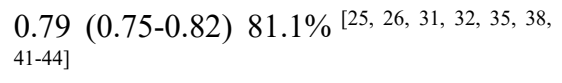 & $1.11(0.69-1.80) 67.6 \%{ }^{[36,37,46]}$ & $\mathrm{N} / \mathrm{A}^{*}$ \\
\hline Prospective cohort & $0.75(0.56-0.98) 0.0 \%{ }^{[18,34]}$ & $0.75(0.56-0.99) 51.5 \%{ }^{[18,30,34]}$ & $1.10(0.71-1.69) 61.2 \%{ }^{[27,39]}$ & $\begin{array}{l}0.71(0.46-1.10) 43.0 \% \\
39]\end{array}$ \\
\hline Case-control & $0.66(0.55-0.80) 28.1 \%{ }^{[28,29]}$ & $0.73(0.60-0.89) 53 . \%^{[28,29]}$ & $\mathrm{N} / \mathrm{A}$ & N/A \\
\hline $\begin{array}{l}\text { Randomized controlled } \\
\text { trial }\end{array}$ & $\mathrm{N} / \mathrm{A}$ & N/A & $1.01(0.79-1.28) 31.2 \%[33,45,47]$ & N/A \\
\hline \multicolumn{5}{|l|}{ Study location } \\
\hline North America & $0.73(0.69-0.77) 75.1 \%[18,25,34,35,38,40]$ & $0.80(0.76-0.84) 78.9 \%{ }^{[18,25,34,35,38,41-44]}$ & $\underset{46]}{1.21}(0.96-1.53) 36.9 \%[36,37,39,45$, & ${ }_{39]}^{1.11}(0.61-2.02) 0.0 \%{ }^{[36,}$ \\
\hline
\end{tabular}


J Pharm Pharm Sci (www.cspsCanada.org) 18(3) 286 - 302, 2015

\begin{tabular}{lllll}
\hline Table 4 Continued... & & & \\
Europe & $0.59(0.53-0.65) 74.5 \%{ }^{[26,29,31,32]}$ & $0.69(0.61-0.77) 63.7 \%^{[26,29-32]}$ & $0.76(0.54-1.08) 0.0 \%{ }^{[27,33,47]}$ & $\mathrm{N} / \mathrm{A}$ \\
Asia & $\mathrm{N} / \mathrm{A}^{*}$ & $\mathrm{~N} / \mathrm{A}^{*}$ & $\mathrm{~N} / \mathrm{A}$ & $\mathrm{N} / \mathrm{A}$ \\
\hline $\begin{array}{l}\text { I= confidence interval; OR= odds ratio; } \mathrm{N} / \mathrm{A}=\text { not available. } \\
\text { *Contain one study, can't get I }{ }^{2} .\end{array}$ & & & \\
\hline
\end{tabular}

